This item was submitted to Loughborough's Research Repository by the author.

Items in Figshare are protected by copyright, with all rights reserved, unless otherwise indicated.

\title{
Ordinary magic, extraordinary performance: psychological resilience and thriving in high achievers
}

\section{PLEASE CITE THE PUBLISHED VERSION}

http://psycnet.apa.org/doi/10.1037/spy0000003

\section{PUBLISHER}

(C) American Psychological Association

\section{VERSION}

AM (Accepted Manuscript)

\section{PUBLISHER STATEMENT}

This work is made available according to the conditions of the Creative Commons Attribution-NonCommercialNoDerivatives 4.0 International (CC BY-NC-ND 4.0) licence. Full details of this licence are available at: https://creativecommons.org/licenses/by-nc-nd/4.0/

\section{LICENCE}

CC BY-NC-ND 4.0

\section{REPOSITORY RECORD}

Sarkar, Mustafa, and David Fletcher. 2019. "Ordinary Magic, Extraordinary Performance: Psychological Resilience and Thriving in High Achievers". figshare. https://hdl.handle.net/2134/22688. 
Ordinary Magic, Extraordinary Performance:

Psychological Resilience and Thriving in High Achievers

Mustafa Sarkar

Middlesex University, United Kingdom

David Fletcher

Loughborough University, United Kingdom

Author Note

Mustafa Sarkar, School of Health and Social Sciences, Middlesex University, United

Kingdom; David Fletcher, School of Sport, Exercise and Health Sciences, Loughborough

University, United Kingdom.

Mustafa Sarkar is now at the School of Sport, Exercise and Health Sciences,

Loughborough University, United Kingdom.

This work was funded in part by Lane4 Management Ltd [grant number J12644].

The authors thank Dr. Nollaig Frost for her guidance on qualitative methods and comments on an early draft of the manuscript.

Correspondence concerning this article should be addressed to Mustafa Sarkar,

School of Sport, Exercise and Health Sciences, Loughborough University, Epinal Way,

Loughborough, Leicestershire LE11 3TU, United Kingdom. Telephone: 4415-0922-8450.

Fax: 4415-0922-6301. E-mail: M.Sarkar@lboro.ac.uk 


\section{Abstract}

2 Although resilience has been referred to as "ordinary magic" (Masten, 2001, p. 227) that is more common than once thought, the majority of research in this area has sampled

4 individuals who have been required to react to potentially traumatic events outside of their control. The findings of this work, however, are not easily applicable to those who actively seek to engage with challenging situations that present opportunities for them to raise their performance level. The purpose of this study was, therefore, to identify and explore resilient qualities that enable high achievers to thrive and perform at extraordinary levels. Thirteen high achievers (9 male and 4 female) from eleven professions were interviewed in the UK, and interpretative phenomenological analysis was used to identify resilient qualities that enabled the participants to thrive in pressured environments. Results revealed six superordinate themes that characterized resilience and thriving: positive and proactive personality, experience and learning, sense of control, flexibility and adaptability, balance and perspective, and perceived social support. The data highlights the multifaceted nature of resilience comprising a constellation of personal qualities that enable high achievers to excel in demanding contexts. The themes are discussed in relation to previous research findings and in terms of their implications for practicing psychologists. It is anticipated that these themes will provide practitioners with an insight into the distinct features of resilience and thriving in high achievers and help individuals to attain success and well-being in their careers. Keywords: excellence, human performance, protective factors, resilient qualities, work stress. 
Ordinary Magic, Extraordinary Performance:

Psychological Resilience and Thriving in High Achievers

Resilience - the capacity to cope with stress and catastrophe - is the hottest new topic in psychology, medicine and social sciences ... Resilience is a critical skill. In a stressful, fast-changing world it can even help inoculate against mental illness while boosting achievement levels and productivity (Hoggard, 2009, p. 35)

Comments such as the above by Liz Hoggard, a journalist based in the United

Kingdom, illustrate that resilience is gathering popularity as a topic of inquiry in the

psychosocial sciences. In her seminal paper, Masten (2001) discussed resilience processes in human development and concluded that, contrary to popular mass media and scholarly work portrayal, resilience is a common phenomenon. She argued that resilience does not come from rare and special qualities, but from "the everyday magic of ordinary, normative human resources" (p. 235). Bonanno (2004) supported this perspective, reviewing evidence indicating that the majority of individuals exposed to potentially traumatic events do not exhibit chronic symptom profiles and that many show the type of healthy functioning associated with resilience (see also Bonanno, 2012; Bonanno, Westphal, \& Mancini, 2011). Within the field of psychology, resilience has been defined as a "dynamic process encompassing positive adaptation within the context of significant adversity" (Luthar, Cicchetti, \& Becker, 2000, p. 543) and as "the positive role of individual differences in people's response to stress and adversity" (Rutter, 1987, p. 316). These individual differences, which are more commonly referred to as protective factors in the literature, have been examined by scholars seeking to identify the qualities of resilient individuals (see, for a review, Luthar, 2006; Masten \& Reed, 2002; Rutter, 2000). In terms of the extant research in this area, studies have typically been conducted with high-risk children, adults, families, and communities that have been exposed to difficult circumstances in their lives, such as 
1 terrorism (Moscardino, Axia, Scrimin, \& Capello, 2007), natural disaster (Rajkumar,

2 Premkumar, \& Tharyan, 2008), serious illness (Betancourt et al., 2011), and political violence

3 (Gelkopf, Berger, Bleich, \& Silver, 2012). Fletcher and Sarkar (2012) recently observed that

4 the majority of resilience research has sampled individuals who have been required to react to

5 potentially traumatic events outside of their control. They pointed out, however, that the

6 findings of this work are not easily applicable to those who actively seek to engage with

7 challenging situations that present opportunities for them to raise their performance level.

8 This enhanced level of functioning is conceived, in the present study, to reflect the construct

9 of thriving (cf. Carver, 1998).

10 In one of the first papers to discuss the potential links and distinctions between

11 resilience and thriving, Carver (1998) noted that resilience is similar to thriving in that they

both reflect a capacity for positive adaptation (see also Sutcliffe \& Vogus, 2003). In

differentiating between the constructs, he suggested that the term resilience denotes a

restoration to healthy levels of functioning, whereas thriving refers to the ability of

individuals to function at a consistently higher level. Carver further argued that, in contrast to resilience, "thriving . . . does not depend on the occurrence of a discrete traumatic event or longer term trauma" (p. 245). Similarly, when distinguishing between resilience and thriving, Spreitzer, Sutcliffe, Dutton, Sonenshein, and Grant (2005) observed that the conceptualization of resilience typically encompasses adversity, whereas "thriving can occur with or without adversity" (p. 358). Thus, resilience refers to the ability to maintain relatively stable, healthy levels of psychological and physical functioning following an adverse event (cf. Bonanno, 2004), whereas thriving represents a consistently higher level of functioning that is not necessarily dependent on the occurrence of a potentially traumatic event (cf. Carver, 1998). 
1 lifespan development (Benson, \& Scales, 2009; Bundick, Yeager, King, \& Damon, 2010) and work performance (Carmeli \& Spreitzer, 2009; Porath, Spreitzer, Gibson, \& Garnett, 2012). Most recently, Porath et al. (2012) developed and validated a measure of thriving at work. They found support for a two-dimensional structure of thriving; namely, the experience of vitality and learning. Furthermore, they reported evidence for the convergent and discriminant validity of the measure by comparing thriving to theoretically related constructs, comprising positive and negative affect, learning and performance goal orientations, proactive personality, and core self-evaluations. They also established a link between thriving and adaptive behaviors, including career development initiative and individual job performance. domains, such as sport (see, e.g., Fletcher \& Sarkar, 2012), business organizations (see, e.g.,

Gittell, Cameron, Lim \& Rivas, 2006), law enforcement (see, e.g., Miller, 2008), medical services (see, e.g., Jackson, Firtko, \& Edenborough, 2007), military institutions (see, e.g., Reivich, Seligman, \& McBridge, 2011), and education (see, e.g., Reis, Colbert, \& Hebert, 2005). In one of the few sport-related resilience studies, Martin-Krummm, Sarazzin, Peterson, and Framose (2003) examined the relationship between explanatory style and resilience in a group of recreational basketball players. Following failure feedback in a dribbling task, optimistic participants were found to be more confident, less anxious, and perform better, than pessimistic participants. Although this study demonstrates the processes by which explanatory style affects sport performance, it is not without its limitations. Firstly, the study focused on a single psychological attribute (viz. explanatory style) which precluded participants from providing a more complete insight into resilient qualities. Secondly, the findings of this work were based on recreational athletes and it would not be appropriate to 
generalize to athletes who perform at higher competitive levels.

Turning to the business context, researchers have sought to identify the factors that promote organizational resilience (see, e.g., Gittell et al., 2006; Lengnick-Hall, Beck, \& Lengnick-Hall, 2011). These qualities include: a climate of reciprocal trust and interdependence, problem solving processes tied to organizational learning, and human resource flexibility. Regarding studies that have searched for the attributes that protect employees from the stressors they encounter, only a limited number of articles have been published and these have typically lacked an underpinning evidence-base (see, Coutu 2002; Sonnenfeld \& Ward, 2008). To illustrate, based on her personal musings and a cursory perusal of the literature, Coutu (2002) concluded that resilient employees possess three main characteristics: the ability to face reality with staunchness, to find meaning out of hardship, and to improvise solutions.

Researchers have begun to investigate the construct of resilience in the law enforcement and medical services (see, e.g., Ablett \& Jones, 2007; Miller, 2008; Jackson et al., 2007; Paton et al., 2008). For example, Miller (2008) identified a core set of protective factors in police officers such as a learning attitude towards the profession, adequate emotional control, a sense of optimism, and the willingness to seek help from others. Moreover, in a study of operating room nurses, five variables (viz. hope, self-efficacy, coping, control, competence) were found to explain $60 \%$ of the variance in resilience (Jackson et al., 2007). However, 40\% of the variance was still unaccounted for and, therefore, the authors recognized the need for more idiographic research to gain a better understanding of resilience in medical personnel. In an attempt to address this issue, Ablett and Jones (2007) identified and explored the resilient qualities of palliative care staff using the qualitative method of interpretative phenomenological analysis (IPA). Ten themes emerged including an active choice to work in palliative care, past personal experiences, personal attitudes towards 
work, and aspects of job satisfaction.

What is becoming clear from the findings of resilience research across various performance domains is that resilience is a pivotal capacity not only for individuals reacting to potentially traumatic events, but also for those who choose to operate in demanding environments (cf. Fletcher \& Sarkar, 2012). Indeed, Coutu (2002) asserted that:

More than education, more than experience, more than training, a person's level of resilience will determine who succeeds and who fails. That's true in the cancer ward, it's true in the Olympics, and it's true in the boardroom (p. 47)

Despite this observation and the notion that resilience is a more common phenomenon than previously thought, little is known about individuals' capacity to thrive on pressure and perform at extraordinary levels. The purpose of this study was, therefore, to identify and explore resilient qualities that enable high achievers to thrive in pressured environments.

\section{Method}

\section{Research Design}

This study was deemed best suited to qualitative methods in view of the scant knowledge of psychological resilience and thriving in high achievers. As Bonnano (2012) recently asserted, "qualitative studies of putatively resilient samples ... provide a valuable source of new ideas and information, especially in populations that have not yet benefited from systematic study" (p. 755). Qualitative methods are also particularly appropriate for better understanding the complexity of psychosocial phenomenon, such as resilience and thriving in the context of high performance. Indeed, qualitative researchers in this area have stated that such an approach can account for the specific context in which resilience and thriving is manifested (see Massey, Cameron, Ouellette, \& Fine, 1998; Ungar, 2003). In terms of an underpinning philosophical orientation to this study, we develop knowledge through a process of interpretation (i.e., epistemologically interpretivist) and believe in 
retaining a balanced outlook (i.e., ontologically realist).

In this study, an interpretative phenomenological approach (Smith \& Osborn, 2003) was utilized to explore individuals' subjective experiences. The aim of IPA is to investigate how people make sense of their personal world and has its origins in phenomenology, hermeneutics, and idiography (Smith \& Osborn, 2003). The approach stems from a phenomenological tradition that seeks to explore the meaning participants' impart on the phenomenon being investigated (Brocki \& Wearden, 2006; Reid, Flowers \& Larkin, 2005). It involves a two-part interpretation with hermeneutic influences whereby the participants are trying to make sense of their world, and the researcher is trying to make sense of the participants trying to make sense of their world (Smith \& Osborn, 2003). IPA is idiographic in its commitment to analyze each case in detail, and attempts to provide an indication of theme convergence and divergence. Indeed, Smith (2011) asserted that "the best IPA studies are concerned with ... not only presenting both shared themes but also pointing to the particular way in which these themes play out for individuals" (p. 10). The importance of the narrative portrayal remains paramount in IPA with the final analysis providing a detailed interpretative analysis of themes; this is in comparison to content analysis, which can produce a quantitative analysis of discrete categories from qualitative data (Brocki \& Wearden, 2006). Furthermore, studies using IPA tend to employ purposive sampling; that is, the experiences of the most appropriate persons for the research question being addressed are sought (cf. Ritchie, Lewis, \& Elam, 2003). This is in contrast to other qualitative methods, such as grounded theory, which employ theoretical sampling where the focus of the recruitment is largely based on the emerging concepts until data saturation (Brocki \& Wearden, 2006; cf. O’Reilly \& Parker; in press).

\section{Participants}

In relation to the main focus of the research study, participants were recruited based 
on them demonstrating high levels of functioning, and encountering everyday challenges and major life events during the course of their careers. Guiding the recruitment of the sample was the definition of a high achiever as an individual who had achieved at a high level in his or her performance domain (cf. Jones \& Spooner, 2006). Although it is acknowledged that this description contains an element of subjectivity, the participants in this study were considered to be high achievers on the following grounds: five were recognized in the British Queen's Honours List ${ }^{1}$ for their contribution to their respective fields, two were members of senior management teams in the London Metropolitan Police, two had received a number of highly contested national awards in their particular professions, one was a partner of an internationally recognized accountancy and professional services firm, another was a senior Member of the UK Parliament, and one held two world records in his respective performance domain. During the course of their careers, the participants had encountered various types of everyday challenges including poor working conditions, high workload, demanding clients, organizational politics, peer jealously, and workplace bullying. They had also experienced major life events including serious financial difficulties, discrimination, divorce, and the death of a significant other. Hence, and in line with IPA guidelines (Smith \& Osborn, 2003), the participants in the study were considered to be homogenous in terms of their high levels of achievement and their common ability to thrive whilst operating in demanding situations, conditions, and circumstances.

The sample consisted of 13 high achievers ( 9 men and 4 women) who were recruited from the following 11 performance domains: sport, business, law enforcement, medical services, education, politics, entertainment, extreme environments, aviation and space, media and creative arts, and the public non-profit sector. A wide range of performance domains

\footnotetext{
${ }^{1}$ The British Queen's Honours List is part of the UK honours system where honours "are granted to deserving and high-achieving people from every section of the community ... [and] . . rewards people for merit, service or bravery" ("Queen and Honours", 2008/09).
} 
were sampled to enable the exploration of convergence and divergence in line with IPA guidelines (cf. Smith, 2011). The participants ranged in age from 25 to $68(M=50.6, S D=$ 12.3), had worked in their respective professions for between 8 and 40 years $(M=26.4, S D=$ 10.5), and were operating at a high level at the time of the study.

\section{Procedure}

Following institutional ethical approval, a database of potential participants who met the selection criteria was systematically created, and contact details for each potential participant were acquired. Potential participants were subsequently contacted by email. This correspondence informed them of the purpose of the study, what it entailed for participants, and invited them to participate in an interview. All of the potential participants accepted the invitation and were re-contacted to arrange a mutually convenient time and location to meet. All of the participants provided informed consent prior to the start of data collection. Semistructured interviews were conducted face-to-face by the first author. More specifically, a phenomenological interview was employed to identify and explore resilient qualities that enabled the participants to thrive in pressured environments. This approach was chosen to collect descriptions of the participants' everyday world and to elicit the meaning of the described phenomena (viz. resilience and thriving) as it was experienced by the participants. In a phenomenological semi-structured interview, as Kvale and Brinkmann (2009) noted, the interviewer seeks to interpret the meaning of central themes in the participants' everyday world whilst attempting to obtain open nuanced descriptions of different aspects of both the participants' daily life and specific situations.

In order to better understand the participants' subjective experiences and facilitate the interview process, an interview schedule was developed. A guide was produced in advance to help the interviewer explicitly think about what might be covered in the interview (Smith \& Osborn, 2003). Consistent with IPA guidelines (Smith \& Osborn, 2003), this schedule did not 
1 represent a rigid document, but rather a flexible set of evolutionary questions depending on

2 the direction taken by the participant during the course of the discussion (see the supplementary material for a copy of the full interview guide). This flexible approach was used, within a semi-structured format, to facilitate the participants' ability to tell their own story in their own words, a central premise of IPA (Brocki \& Wearden, 2006). As Smith and Osborn (2003) stated, "[because] IPA researchers wish to analyze in detail how participants perceive and make sense of things which are happening to them, it therefore requires a flexible data collection instrument" (p. 57).

The interviews included a series of open-ended questions and began by asking participants about their career background and personal development (e.g., "can you tell me about events and incidents that you feel have been particularly salient in your experience as a high achiever?"). In line with the purpose of the present study, the focus of the interviews then shifted towards the participants' perceptions of the qualities they felt had enabled them to thrive whilst operating in demanding environments on a daily basis (e.g., "what characteristics do you think helped you to withstand - and thrive on - the pressures you have encountered?"). A few of the questions also explored participants' views on what factors would help them to manage future demands (e.g., "what experiences do you feel will help you to react positively to future challenges?"). Finally, the guide concluded with several questions designed to elicit advice for aspiring high achievers and to evaluate the efficacy of the interview. The interviews, which ranged in duration from 60 to 102 minutes $(M=77.1$, $S D=15.8)$, were digitally recorded and were transcribed verbatim, yielding 214 pages of single spaced text.

\section{Data Analysis}

The interview transcripts were analyzed by the first author using the principles of IPA (Smith, Jarman, \& Osborn, 1999; Smith \& Osborn, 2003). In accordance with the 
1 recommendations of Smith and colleagues $(1999,2003)$, the analysis began with a close

2 reading of the first transcript with initial insights being annotated in the left margin. This

3 idiographic approach to data analysis is a core feature of IPA (Brocki \& Wearden, 2006; Reid

4 et al., 2005; Smith, 2011). The next stage of the analysis involved a translation of these initial

5 notes into emergent themes at a higher level of abstraction and these were annotated in the

6 right margin (Smith \& Osborn, 2003). When selecting and labeling themes, it is important to

7 note that both the prevalence of the associated extracts and the richness of the data were considered. The themes were then examined to make conceptual links between them and,

9 accordingly, themes which appeared related were clustered together (Smith \& Osborn, 2003).

10 As emerging sub-themes were clustered into superordinate themes, the transcript was constantly reviewed to ensure that the interpretation was consistent with what the participant actually said (i.e., an iterative form of analysis). This entire process was repeated for each transcript using the superordinate themes from the first participant to help inform the 
crafts). As Tracy (2010) noted, "this conceptual discrimination of qualitative ends from means provides an expansive or 'big tent' structure for qualitative quality while still celebrating the complex differences amongst various paradigms" (p. 839).

The topic of the research was deemed to be worthy, interesting, timely, and relevant for a variety of audiences. To achieve rich rigor, the study used appropriate and wellestablished data collection and analysis procedures, and provides abundant rich data from significant and distinctive participants. Specifically, this study meets Smith's (2011) criterion for good IPA studies since "for larger sample sizes [greater than 8] researchers should give illustrations from at least three ... participants per theme" (p. 24). Furthermore, in line with a recommendation by Smith (2011), the study points to the specific nuances of certain themes (viz. balance and perspective, perceived social support) to indicate how the themes differ for particular individuals. In accordance with the researchers' ontologically realist beliefs, sincerity was realized through reflexivity about the potential subjective biases and transparency associated with the methods. Specifically, a field log was maintained throughout all phases of data collection and analysis, and a clear account of the research process was recorded and reported to ensure that the reader can understand how the study was conducted (Smith, 2011). To evaluate the credibility of the analysis, the researchers systematically reviewed and discussed all the emergent themes. Although there were some initial disagreements about particular categorizations, agreement was reached through a process of critical and constructive debate. Resonance was achieved through the transferability of findings, specifically by reporting direct quotations from participants, providing rich description, and writing accessibly (cf. Massey et al., 1998; Ungar, 2003). This study’s findings offer new and unique understandings of resilience and thriving in high achievers, and is practically significant for a broad range of practitioners' working in demanding performance environments. The American Psychological Association's (2010) Ethical 
1 Compliance Checklist was completed and, consistent with IPA principles (Smith, 2011) and

2 the researchers' epistemologically interpretivist beliefs, the mutual connectedness between the researcher and participant was valued. Finally, regarding the criteria of meaningful

\section{Results}

The results derived from the data analysis procedures represent the collated interview responses from all 13 participants. Six superordinate themes emerged pertaining to the resilient qualities of high achievers: positive and proactive personality, experience and learning, sense of control, flexibility and adaptability, balance and perspective, and perceived social support. Drawing directly from the experiences of the participants, each theme will be illustrated by direct quotations from the transcripts.

\section{Positive and Proactive Personality}

High achievers possessed numerous positive personality characteristics which enabled them to thrive in challenging situations on a daily basis. These qualities comprised of openness to new experiences, conscientiousness, optimism, and honesty to oneself. The following quote demonstrates how a chair of a national sporting organization remained true to herself and her values during a difficult time in her career:

There was this group of [four] men who wanted me gone [from the organization] primarily because I was a woman and they really bullied me at one point. I mean that's the only word you'd use, [I was] really badly bullied. But I did what I've always done and that is I stuck firmly to my belief that if I was doing what was right for sport somehow it would come through. I think as long as you're clear about what your mission is and as long as you don't allow skeptics to knock you off course, I 
truly believe you can get there.

In addition, high achievers exhibited proactive personality traits, including continually striving for improvement, showing initiative, and constantly seeking out challenge in their careers. To illustrate, a participant who was recognized in the British Queen's Honors List for his services to media and creative industries had an innate desire to engage in numerous work-related activities at the same time:

I want to have a number of things going on [in my career] because if one is not working, I'll get motivation out of another, and if that doesn't work, there are these guys across here you can deal with. So there is always something that you can turn your head back into and get a passion about . . . and I need that. I just need to keep all of these things going on and never let go [of opportunities because] at the back of my mind there will always be something else.

A partner of an internationally recognized accountancy and professional services firm described how he actively sought out opportunities in his career in order to raise his performance level:

I'm not the sort of person that can sit back and just put my feet up. There are a lot of people in [my previous job] who would say 'job for life'. That's just not me. If I don't have a constant challenge and something that's really driving me then I will create it myself somehow ... Being director was a key point for me and then ultimately becoming a partner was a key point for me and I'm now thinking about what's the next thing I can do. What is the next thing that is going to push me forward? A lot of what I tend to focus on is 'how do I win the next big job for the firm?' and that gives me a huge sense of satisfaction and accomplishment.

\section{Experience and Learning}

Being confronted with potentially stressful situations and learning from such incidents 
was perceived to provide a vital foundation for the resilience and thriving of high achievers.

A Borough Commander in the London Metropolitan Police highlighted the importance of drawing on past experiences when faced with difficult circumstances:

[The name of a town] is a very challenging place, but a place where you just carry on learning and uncovering new experiences which you had not had before. And sometimes you get into that 'oh my God' moment when [you think] 'what do I do here'? And despite all the training that you have, there are still issues that present themselves to police officers where you think 'I don't know what to do here'. And that's when you have to use your resilience and draw on your experiences as best you can.

A number of high performers seemed to consciously value challenging experiences, as this quote from an award-winning comedian illustrates: I performed in [country] . . . where they didn't even have any water and they didn't have any electricity. I had to do the gig in the dark and there were no seats because it had been bombed. And to go to places like [country]and [country]and [country] and to know that the stuff I've written can travel and that I can perform this anywhere in the world and people will still laugh. I think it is great being able to translate your life into a universal thing that people anywhere and everywhere around the world can come and appreciate.

Interestingly, those who engaged in formal reflective practices seemed to learn quicker from their experiences and, consequently, this appeared to be a particularly important feature of thriving on pressure. A mountaineer, who holds two world records in his respective field, recalled how he reflected on his performance after facing disappointment in his career: Not succeeding in something ... makes me want to understand why. I probably try to understand why something hasn't happened to me and then reflect that little bit more 
... I take a step back and go slower because I tend to find if I've not done something it's because I've gone too fast and I've missed a point. So having that bit more reflection helps me be better in the future.

\section{Sense of Control}

High achievers felt that having a sense of control in their work-related activities was an important aspect of their resilience and thriving. Specifically, they recognized their active choice to operate in demanding environments, possessed the ability to prioritize activities during dynamic situations, and positively responded to capricious circumstances. The following quote demonstrates how a director of a charitable trust acknowledged that it was his active choice to work in the public non-profit sector:

I've actually been quite good at detaching myself emotionally from issues and that's in a sense of feeling that 'actually I chose to do this job'. You know, nobody made me do this job, I chose to do this job and I came into it with my eyes wide open about the realities. So I was aware that I had to be dealing with things that were personally challenging, which were distressing, which could be emotionally challenging but [I had] a sense of 'actually, I chose to do it' and that [thinking] has helped me. A surgeon, who was recognized in the British Queen's Honors List for her services to medicine, described her ability to prioritize tasks and how this positively impacted her productivity at work:

I do control things quite a lot and I think having a slight control obsession does help you to get through a lot of work in not too much time, and that means being quite ruthless about who comes into your time at various times; so not to the exclusion of everybody else but working out which are the really important things to do and which are the things not to do.

All of the high performers stated that displaying positive responses was a critical 
aspect of their resilience and thriving. The following quote demonstrates how a worldrenowned sports coach took charge of a potentially stressful situation during his tenure as director of coaching:

It's funny the different things that motivate you in life but the [employment] contracts in those days were for two years, you were on probation for two years basically. And I got it into my head that 'if these guys can't work out that I'm the best coach in the world by that time then it's their stupidity not mine'. So I put my head down, went flat out at the changes that had to be [implemented and] bought coach education into a different dimension to the United Kingdom and it started what ... was . . . the best period of athletic success that Britain has ever had from [year] through to [year].

\section{Flexibility and Adaptability}

The ability to be flexible and adaptable was deemed to be a key feature of resilience and thriving for the high performers. To illustrate, they were able to solve problems creatively, demonstrate proficiency when learning novel work practices, react positively to change, remain politically aware when working with others, and display emotional intelligence in a wide variety of situations. For example, a businessman illustrated how being emotionally intelligent was crucial when catering to the needs of two separate clients: Every person has a different aspiration and a different view and ... what matters to one is not what matters to another. We've been in situations before - and this is where the emotional intelligence comes in - where you will sit with people who are interested in the technical detail of something and they want to know every single section number of some tax code. And you can go to another meeting in the same type of industry and all they want to talk about is 'how are you going to support me?' and 'we're going to get to know each other and our families are going to know each other'. You can go from one [client] that's entirely technical ... to one [client] that's 
much more personal and you have to be able to deal with that.

The following quote, from a vice chancellor of a leading university, demonstrates the importance of being politically aware especially when working in an unpredictable environment:

When we were bidding for the medical school we had lots of opposition . . . and there were all sorts of nasty games that were played. And I just became incredibly determined they were not going to beat us. And so we adopted firefighting tactics and worked out who we needed to get on board and playing the politics of it . . Being alert to the politics of a situation . . . is terribly important. You just have to be alert to it all the time and it means picking up the vibes, listening, working out who's pushing for what, going with the flow on some things but working out who's going to be on your side and how to bring everybody on your side.

The majority of high achievers indicated that the ability to adapt positively to change was a critical aspect of resilience, as this quote from a senior Member of Parliament shows: We joke in politics that the only constant is change because there's almost a cycle of events. We see a lot of changes and we have to adapt to those changes. I've come through twenty six years now of having to deal with change, so you become prepared for change and you adapt and you try and make it as seamless as possible. I've always tried to view change as 'change is good' as opposed to 'oh my God here we go again'. So I've always tried to have a bright outlook [and] understand that change happens. Change happens in the world so why should we be any different? So it's just [a question of] facing up to it with vigor and determination and to accept it and move with it. You can't fight it. I learnt that you can't fight it; you get sidelined very quickly if you want to fight things so roll with it and make the most of it.

\section{Balance and Perspective}


Maintaining a balance between one's work and other aspects of life, and having a sense of perspective in life were essential characteristics of resilience and thriving for the high performers. They indicated the importance of achieving an optimal work-life balance, retaining a broad sense of identity that was not too focused on a career-related role, working in various countries to gain an appreciation of different outlooks, and creating time for oneself. The following quote illustrates how a superintendent in the London Metropolitan police recognized the need to take care of his health after long hours at work:

Once you become an Inspector or above . . you have to manage your own time. Yesterday I was on duty for over 14 hours because I had stuff in the morning and I had an evening meeting. But what I will try and do at some point is to claw a couple of hours back on that. You're only salaried for a forty hour week but the reality is that it's a hugely pressing business and you need, at times, to do more than that. But again you have to manage your own time around that. Talking about resilience you have to ... recognize that there is a limit to how many days you can do because the law of diminishing returns means that at a point you become less effective ... so you have got to look after yourself in that way.

A businessman felt that it was necessary to be involved with conventional, day-to-day activities to retain a sense of perspective in one's life:

I think it's important, as you move through organizations and no matter how much money you earn, [to] actually still quite comfortably enjoy going to the pub and having a pint every so often and doing things that are just mainstream in its own right [so] you don't lose touch with reality. Because quite often you find people, especially investment bankers, who tend to say 'a few thousand pounds here, that's not very significant' and you think 'actually a few thousand pounds to somebody else is significant'. It's all about perspective in life and I think not losing that perspective is 
important. Interestingly, although the majority of high achievers believed that one's work and

life roles improved the quality of each other, a couple of participants weren't entirely comfortable with the notion of a work-life balance, as the following quote demonstrates: In my area we deal with a lot of very senior people who are quite often in the press and ... their expectations of you are incredibly high. I suppose the hardest piece in all of this is how you balance all of that within the context of your work-life balance, which actually I never liked that term because it sounds to me like it's a trade- off. It's not so much of a balance as getting the right equilibrium that works for you. Balance suggests that it has to be even when, in fact in reality, it never is that way. But you do have to have a perspective that allows you to get yourself outside work and ... you need to find the mechanism to allow that to happen. So whether that's spending two hours in the gym a day, going out for a walk, or reading the newspaper, these things are quite demanding to achieve but they're very important to achieve.

\section{Perceived Social Support}

High achievers perceived that high quality social support was available to them and they considered this to be an important aspect of their resilience and thriving. This included support from people within their performance domain (e.g., colleagues and mentors), and support from individuals outside their performance domain (e.g., family and friends). According to a senior administrator for the UK's government space agency, his partner helped to protect him from the time-related pressures of his job: I feel very fortunate that my wife has been very supportive. Last Monday I started at 5:30 in the morning and I didn't finish until 1:30 the following morning. I didn't see the kids . . . and then I'm back at work the following day. It does impinge on you. I'm struggling to . . . put my finger on how I feel I've been supported but just through 
that understanding, just through never making a fuss about things, [and] not having a long face when being woken up in the middle of the night by a phone call which requires some action [on my part].

A number of high performers recalled the help they received from their personal assistant (PA), with a vice chancellor suggesting that the rapport she had created with her PA gave her the chance to air her grievances:

I have a fantastic PA ... I know that [Name] will deal with a situation as I would deal with it. She's the front line for everybody so, if she's rude to people, that impacts me; she's not, she's wonderful, she's endlessly patient with people and she's tough as well. So my relationship with her ... I can come in and say 'you won't believe what's just happened and I'm going to scream and shout', because you need that. Interestingly, however, one comedian felt that peers operating in the same field impeded her career development and she attributed her resilience and thriving solely to her positive and proactive personality:

Nobody really went out of their way to help me ... In fact . . . a lot of comedians were actually quite jealous and they actually hindered my [career] progress . . . I think when it comes down to it the only thing that kept me going was my own determination - that I want to do this and I want to be the best at it - and I think it has be the only factor because there was no other.

\section{Discussion}

Using IPA techniques, this study identified and explored resilient qualities that enable high achievers to thrive in pressured environments. The findings revealed six superordinate themes that characterized resilience and thriving: positive and proactive personality, experience and learning, sense of control, flexibility and adaptability, balance and perspective, and perceived social support. The data highlight the multifaceted nature of 
1 resilience comprising a constellation of personal qualities that enable high achievers to excel

2 in demanding contexts. It is anticipated that these themes will provide practicing psychologists with an insight into the distinct features of resilience and thriving in high achievers and help individuals to attain success and well-being in their careers.

There are, perhaps, two overarching messages to emerge from this study and the findings. The first message is that, during pressured times, high achievers appear to take personal responsibility for their thoughts, feelings and behaviors. For example, the positive and proactive personalities of the participants stimulated them to identify opportunities in the environment and underpinned their strong drive towards action. Previous research has found a proactive personality to be an important characteristic in predisposing one to higher levels of performance in various work settings, including politics (Deluga, 1998), business (Rauch \& Frese, 2007), and sport (Fletcher \& Sarkar, 2012). More specifically, research has found that a proactive disposition protects individuals from the potential negative effect of stressors (i.e., resilience; Fletcher \& Sarkar, 2012) and also leads to consistently higher levels of functioning (i.e., thriving; Erdogan \& Bauer, 2005; Rauch \& Frese, 2007). In the current study, the high achievers' proactive personality traits appeared to facilitate career-related behaviors including career planning, the implementation of new ideas, and the gaining of information regarding power structures within an organization. Interestingly, Seibert, Kraimer, and Crant (2001) found that a proactive personality indirectly related to objective (salary and promotions) and subjective (career satisfaction) indicators of career success through behavioral processes including actively managing one's own career, creating innovative solutions to problems, and taking initiative in understanding the political landscape.

Another example relating to the notion of individual accountability is high achievers propensity to maintain a sense of control during challenging circumstances intertwined with a 
1 belief that they possessed, or were able to access, the necessary resources to withstand the demands they encountered. They typically perceived that a variety of social agents, from within and outside their performance domain, would provide support and assistance if needed. Specifically, tangible support from colleagues and mentors together with emotional support from family and friends were instrumental factors in them withstanding - and thriving on - pressure. Although the perception of support from family and friends has been identified in various performance domains in the context of resilience (see, e.g., Fletcher \& Sarkar, 2012; Jackson et al., 2007; Miller, 2008; Reis et al., 2005), the participants in this study also believed that specific support from colleagues and mentors related more directly to their thriving capacity. In line with the identified features of successful family physicians (Jensen et al., 2008), the high achievers felt that they were assisted by competent staff, benefited from operating within multidisciplinary teams, and obtained good mentoring. By taking responsibility for their thoughts, feelings and actions, high achievers rarely passively

react to the stressors they encounter; rather they make deliberate and decisive decisions relating to their particular performance context.

A second overarching message to emerge from this study's findings is that high performers appeared to be committed to personal development and mastery. To illustrate, in order to raise their performance level, high achievers actively engaged with a range of challenging situations including poor working conditions, imposed change, and organizational politics. Importantly, experience of these demands presented opportunities for growth and, when adaptation occurred, appeared to protect high achievers from the potential negative effect of similar subsequent stressors. Within the psychology literature, this phenomenon has been described as stress inoculation (see, e.g., Neff \& Broady, 2011; Seery, Holman, \& Silver, 2010). Specifically, exposure to ongoing demands, such as workplace stressors, is believed to have a shielding effect since it provides individuals with an 
1 opportunity to learn from their experiences. In the present study, high achievers who engaged

2 in purposeful reflection seemed to accelerate their learning since the reflective process

offered a means of generating self-awareness, formulating new knowledge, and in some cases, empowering individuals to implement change (cf. Ekeburugh, 2007; Richards, Mascarenhas, \& Collins, 2009). The learning dimension identified in this study provides partial support for Porath et al.'s (2012) two-dimensional structure of thriving (viz. learning and vitality). More specifically, the acquisition and application of knowledge and skills was considered to be an important aspect of participants' high levels of achievement.

Interestingly, vitality did not appear to characterize resilience and thriving in our sample of high performers, which appears to provide some support for Benson and Scales's (2009) statement that "thriving persons do not [italics added] always exhibit positive affect" (p. 87). Regarding their dedication to personal improvement and excellence, high achievers also engaged in numerous non-work experiences to help them withstand the demands they encountered. For example, some individuals sought out regular pastimes, such as exercising, which appeared to result in perceptions of competence and feelings of detachment from work. Other high performers were involved with intermittent relaxing activities, such as meeting friends for dinner, which seemed to be related to emotional states, such as joviality and serenity. Sonnentag and Fritz (2007) proposed four distinct off-job experiences that are essential in capturing individuals' recuperation processes; namely, psychological detachment from work, relaxation, mastery, and control. Empirical studies have confirmed that these experiences are positively related to indicators of well-being (Fritz, Sonnentag, Spector, \& McInroe, 2010; Siltaloppi, Kinnunen, \& Feldt, 2009). A possible explanation for how experiences away from work protect individuals from negative consequences is that work demands require psychological resources to regulate thoughts, feelings and behaviors, and thus engaging in activities that no longer tax these resources may subsequently help the 
regeneration of self-regulation capacities (cf. Grawitch, Barber, \& Justice, 2010).

When interpreting the findings of a qualitative investigation, it is important to recognize some of the strengths and limitations of the approach. A notable strength of the study, in our view, is the characteristics of the sample. Specifically, the high achievers who participated in the interviews were some of the most eminent figures in their respective fields. Indeed, it has been suggested that the study of significant samples (i.e., collections of participants who are distinguished in some way) greatly enriches psychological science, and that "one of the best ways of demonstrating the broader relevance of psychology is to show that it helps to explain the ... important people of the real world, including leaders, creators, champions, sages, and celebrities" (Simonton, 1999, p. 442). Utilizing semi-structured interviews to collect the data from these individuals ensured that insightful vignettes and authentic data rich information relating to psychological resilience and thriving in high achievers was gleaned. Notwithstanding these strengths, a potential limitation is that the participants were interviewed only once during the course of their careers and this limited the examination of the dynamic nature of resilience and thriving (cf. Fletcher \& Sarkar, 2013; Porath et al., 2012). Research investigating resilience and thriving over time across work and non-work contexts will provide a better understanding of the ongoing process of managing potentially stressful situations in different environments.

The findings reported here suggest that psychological resilience and thriving in high achievers is likely to be a fruitful avenue for future inquiry. Pertinent questions in this area include the following: Are there any idiosyncratic differences in resilient qualities for attaining versus sustaining high performance? To what extent is resilience and thriving in high achievers innate versus learned? What is the relationship between resilience and thriving and, more specifically, to what extent are significant adversities and subsequent growth instrumental in the development and realization of high achievement? Does thriving in work 
transfer to other life domains, or does it leave very little space for other aspects of personal development? In the context of high performance, the social phenomenon of tall poppy syndrome - that is, the tendency to resent and criticize highly successful people because their talents distinguish them from their peers - is particularly relevant (cf. Grove \& Paccagnella, 1995; Kirkwood, 2007). In the present study, for example, participants identified instances of bullying and jealousy and this appeared to be related to their career achievements. Future studies in this area should explore high achievers' experiences of tall poppy syndrome and strategies for managing its occurrence and impact. In line with the approach adopted in this study, future researchers should carefully define and distinguish between conceptually similar salutogenic constructs under investigation, such as mental toughness, coping, buoyancy, hardiness, posttraumatic growth, stress-related growth, and benefit finding (cf. Wadey, Clark, Podlog, \& McCullough, 2013). Researchers should also consider examining the role of diverse biological processes, such as neuroendocrinology and emotion regulation capacities, in human resilience and thriving (see Cicchetti \& Curtis, 2007; Luthar, 2006).

In terms of the praxis of this investigation, there are a number of practical implications of the findings and themes presented. Organizations could use the results of this study to design career management programs that empower individuals to take personal responsibility for their thoughts, feelings and actions in potentially stressful situations. Specifically, aspiring high achievers should be urged to update their skills, expand their core competencies, engage in career planning, and involve themselves in mentoring relationships. Psychologists working in demanding performance environments should also help individuals cultivate a commitment to personal development and mastery. It is crucial that practitioners carefully manage individuals' immediate environment to optimize the adversities they encounter to stimulate and foster the development of resilient qualities that will protect them from negative consequences. Where possible, aspiring high performers should be encouraged 
to actively seek out appropriately challenging situations since this will make subsequent demands seem more manageable, leading to improvements in performance (cf. Seery et al., 2010). To illustrate, during exposure to a realistic critical incident simulation, a policespecific training program was found to enhance stressor-specific adaptive responses, increase controllability, and simultaneously improve job performance (Arnetz, Nevedal, Lumley, Backman, \& Lublin, 2009). To further assist individuals in their dedication to personal improvement and excellence, psychologists should encourage those with a desire to achieve at the highest level to seek out non-work activities associated with mastery experiences, feelings of detachment from work, and relaxation. Examples of activities that may help provide a balance and perspective between one's work and life include travelling, learning a new hobby, reading a book, or going for a walk.

The findings of this study resonate with Masten's (2001) conclusion that "what began as a quest to understand the extraordinary has revealed the power of the ordinary" (p. 235).

Certainly, the experiences of the high achievers interviewed in this study indicate that resilient qualities are important contributory factors to them thriving in pressured environments. However, just how common these qualities are in those attempting to achieve at the highest levels remains largely unknown. Although it is becoming established that resilience is common (Bonanno, 2004; Masten, 2001) when humans are required to react to events outside their control (Fletcher \& Sarkar, 2012; cf. Bonanno, 2012; Bonanno, Westphal, \& Mancini, 2011), it maybe that when humans actively seek out challenging situations, the qualities used to thrive on pressure become the exception rather than the norm, particularly at the highest levels of human endeavor. How humans rise above their comfort zone and avoid regressing to the norm represents a fascinating area of future performance psychology research. 


\section{References}

Ablett, J. R., \& Jones, R. S. P. (2007). Resilience and well-being in palliative care staff: A qualitative study of hospice nurses' experience of work. Psycho-Oncology, 16, 733740. doi: 10.1002/pon.1130

American Psychological Association. (2010). Publication manual of the American Psychological Association (6 ${ }^{\text {th }}$ ed.). Washington, DC: American Psychological Association.

Arnetz, B. B., Nevedal, D. C., Lumley, M. A., Backman, L., \& Lublin, A. (2009). Trauma resilience training for police: Psychophysiological and performance effects. Journal of Police and Criminal Psychology, 24, 1-9. doi: 10.1007/s11896-008-9030-y

Benson, P. L., \& Scales, P. C. (2009). The definition and preliminary measurement of thriving in adolescence. Journal of Positive Psychology, 4, 85-104. doi: $10.1080 / 17439760802399240$

Betancourt, T. S., Meyers-Ohki, S., Stulac, S. N., Barrera, A. E., Mushashi, C., \& Beardslee, W. R. (2011). Nothing can defeat combined hands (Abashize hamwe ntakibananira): Protective processes and resilience in Rwandan children and families affected by HIV/AIDS. Social Science \& Medicine, 73, 603-701. doi:10.1016/j.socscimed.2011.06.053

Bonanno, G. A. (2004). Loss, trauma, and human resilience: Have we underestimated the human capacity to thrive after extremely adverse events? American Psychologist, 59, 20-28. doi: 10.1037/0003-066X.59.1.20

Bonanno, G. A. (2012). Uses and abuses of the resilience construct: Loss, trauma, and healthrelated adversities. Social Science \& Medicine, 74, 753-756. doi: 10.1016/j.socscimed.2011.11.022

Bonanno, G. A., Westphal, M., \& Mancini, A. D. (2011). Resilience to loss and potential 
trauma. Annual Review of Clinical Psychology, 7, 511-535. doi: 10.1146/annurevclinpsy-032210-104526

Brocki, J. M., \& Wearden, A. J. (2006). A critical evaluation of the use of interpretative phenomenological analysis (IPA) in health psychology. Psychology and Health, 21, 87-108. doi: 10.1080/14768320500230185

Bundick, M. J., Yeager, D. S., King, P. E., \& Damon, W. (2010). Thriving across the life span. In W. F. Overton, \& R. M. Lerner (Eds.), Handbook of lifespan development (pp. 882-923). New York City, NY: John Wiley \& Sons.

Carmeli, A., \& Spreitzer, G. M. (2009). Trust, connectivity, and thriving: Implications for innovative behaviors at work. Journal of Creative Behavior, 43, 169-191. doi: 10.1002/j.2162-6057.2009.tb01313.x

Carver, C. S. (1998). Resilience and thriving: Issues, models, and linkages. Journal of Social Issues, 54, 245-266. doi: 10.1111/j.1540-4560.1998.tb01217.x

Cicchetti, D., \& Curtis, W. J. (Eds.). (2007). A multilevel approach to resilience [Special Issue]. Development and Psychopathology, 19, 627-955.

Coutu, D. (2002, May). How resilience works. Harvard Business Review, 46-55.

Deluga, R. J. (1998). American presedential proactivity, charismatic leadership, and rated performance. Leadership Quarterly, 9, 265-291. doi: 10.1016/S1048-9843(98)900303

Ekeburgh, M. (2007). Lifeworld based reflection and learning: A contribution to the reflective practice in nursing and nursing education. Reflective Practice, 8, 331-343. doi: 10.1080/14623940701424835

Erdogan, B., \& Bauer, T. N. (2005). Enhancing career benefits of employee proactive personality: The role of fit with jobs and organizations. Personnel Psychology, 58, 859-891. doi: 10.1111/j.1744-6570.2005.00772.x 
1 Fletcher, D., \& Sarkar, M. (2012). A grounded theory of psychological resilience in Olympic champions. Psychology of Sport and Exercise,13, 669-678. doi: 10.1016/j.psychsport.2012.04.007

Fletcher, D., \& Sarkar, M. (2013). Psychological resilience: A review and critique of definitions, concepts, and theory. European Psychologist, 18, 12-23. doi: $10.1027 / 1016-9040 / \mathrm{a} 000124$

Fritz, C., Sonnentag, S., Spector, P. E., \& McInroe, J. A. (2010). The weekend matters: Relationships between stress recovery and affective experiences. Journal of Organizational Behavior, 31, 1137-1162. doi: 10.1002/job.672

Gelkopf, M., Berger, R., Bleich, A., \& Silver, R. C. (2012). Protective factors and predictors of vulnerability to chronic stress: A comparative study of 4 communities after 7 years of continuous rocket fire. Social Science \& Medicine, 74, 757-766. doi: 10.1016/j.socscimed.2011.10.022

Gittell, J. H., Cameron, K., Lim, S., \& Rivas, V. (2006). Relationships, layoffs, and organizational resilience: Airline industry responses to September 11. Journal of Applied Behavioral Science, 42, 300-329. doi: 10.1177/0021886306286466

Grawitch, M. J., Barber, L. K., \& Justice, L. (2010). Rethinking the work-life interface: It's not about balance, it's about resource allocation. Applied Psychology: Health and Well-being, 2, 127-159. doi: 10.1111/j.1758-0854.2009.01023.x

Grove, R. J., \& Paccagnella, M. (1995). Tall poppies in sport: Attitudes and ascribed personality traits. Australian Psychologist, 30, 86-91. doi: $10.1080 / 00050069508258909$

Guba, E. G., \& Lincoln, Y. S. (2005). Paradigmatic controversies, contradictions, and emerging confluences. In N. K. Denzin, \& Y. S. Lincoln (Eds.), The Sage handbook of qualitative research (pp. 191-216). Thousand Oaks, CA: Sage. 
1 Hoggard, L. (2009, December 7). How high is your resilience quotient? London Evening Standard, p. 35.

Jackson, D., Firtko, A., \& Edenborough, M. (2007). Personal resilience as a strategy for surviving and thriving in the face of workplace adversity: A literature review. Journal of Advanced Nursing, 60, 1-9. doi: 10.1111/j.1365-2648.2007.04412.x

Jensen, P. M., Trollope-Kumar, K., Waters, H., \& Everson, J. (2008). Building physician resilience. Canadian Family Physician, 54, 722-729.

Jones, G., \& Spooner, K. (2006). Coaching high achievers. Consulting Psychology Journal: Practice and Research, 58, 40-50. doi: 10.1037/1065-9293.58.1.40

Kirkwood, J. (2007). Tall poppy syndrome: Implications for entrepreneurship in New Zealand. Journal of Management \& Organization, 13, 366-382. doi: 10.5172/jmo.2007.13.4.366

Kvale, S., \& Brinkmann, S. (2009). Interviews: Learning the craft of qualitative research interviewing. Thousand Oaks, CA: Sage.

Lengnick-Hall, C. A., Beck, T. E., \& Lengnick-Hall, M. L. (2011). Developing a capacity for organizational resilience through strategic human resource management. Human Resource Management Review, 21, 243-255. doi:10.1016/j.hrmr.2010.07.001

Luthar, S. S. (2006). Resilience in development: A synthesis of research across five decades. In D. Cicchetti, \& D. Cohen (Eds.), Developmental psychopathology: Risk, disorder, and adaptation (pp. 739-795). New York City, NY: Wiley.

Luthar, S. S., Cicchetti, D., \& Becker, B. (2000). The construct of resilience: A critical evaluation and guidelines for future work. Child Development, 71, 543-562. doi: $10.1111 / 1467-8624.00164$

Martin-Kruum, C. P., Sarrazin, P. G., Peterson, C., \& Famose, J-P. (2003). Explanatory style and resilience after sports failure. Personality and Individual Differences, 35, 1685- 
1695. doi:10.1016/S0191-8869(02)00390-2

Massey, S., Cameron, A., Ouellette, S., \& Fine, M. (1998). Qualitative approaches to the study of thriving: What can be learned? Journal of Social Issues, 54, 337-355. doi: 10.1111/j.1540-4560.1998.tb01222.x

Masten, A. S. (2001). Ordinary magic: Resilience processes in development. American Psychologist, 56, 227-238. doi: 10.1037/0003-066X.56.3.227

Masten, A. S., \& Reed, M. J. (2002). Resilience in development. In C. R. Snyder, \& S. J. Lopez (Eds.), Handbook of positive psychology (pp. 74-78). New York City, NY: Oxford University Press.

Miller, L. (2008). Stress and resilience in law enforcement training and practice. International Journal of Emergency Mental Health, 10, 109-124.

Moscardino, U., Axia, G., Scrimin, S., \& Capello, F. (2007). Narratives from caregivers of children surviving the terrorist attack in Beslan: Issues of health, culture, and resilience. Social Science \& Medicine, 64, 1776-1787. doi:10.1016/j.socscimed.2006.11.024

Neff, L. A., \& Broady, E. F. (2011). Stress resilience in early marriage: Can practice make perfect? Journal of Personality and Social Psychology, 101, 1050-1067. doi: $10.1037 / \mathrm{a} 0023809$

O’Reilly, M., \& Parker, N. (in press). 'Unsatisfactory saturation': A critical exploration of the notion of saturated sample sizes in qualitative research. Qualitative Research.

Paton, D., Violanti, J. M., Johnston, P., Burke, K. J., Clarke, J., \& Keenan, D. (2008). Stress shield: A model of police resiliency. International Journal of Emergency Mental Health, 10, 95-108.

Porath, C., Spreitzer, G., Gibson, C., \& Garnett, F. G. (2012). Thriving at work: Toward its measurement, construct validation, and theoretical refinement. Journal of 
RESILIENCE AND THRIVING IN HIGH ACHIEVERS

Organizational Behavior, 33, 250-275. doi: 10.1002/job.756

Queen and Honours (2008/09). Retrieved April 4, 2013, from http://www.royal.gov.uk/MonarchUK/Honours/Honours.aspx

Rajkumar, A. P., Premkumar, T. S., \& Tharyan, P. (2008). Coping with the Asian tsunami: Perspectives from Tamil Nadu, India on the determinants of resilience in the face of adversity. Social Science \& Medicine, 67, 844-853. doi:10.1016/j.socscimed.2008.05.014

Rauch, A., \& Frese, M. (2007). Let's put the person back into entrepreneurship research: A meta-analysis on the relationship between business owners' personality traits, business creation, and success. European Journal of Work and Organizational Psychology, 16, 353-385. doi: 10.1080/13594320701595438

Reid, K., Flowers, P., \& Larkin, M. (2005). Exploring lived experience: An introduction to interpretative phenomenological analysis. The Psychologist, 18, 20-23.

Reis, S. M., Colbert, R. D., \& Hebert, T. P. (2005). Understanding resilience in diverse, talented students in an urban high school. Roeper Review, 27, 110-120. doi: $10.1080 / 02783190509554299$

Reivich, K. J., Seligman, M. E. P., \& McBride, S. (2011). Master resilience training in the U.S. army. American Psychologist, 66, 25-34. doi: 10.1037/a0021897

Richards, P., Mascarenhas, D. R. D., \& Collins, D. (2009). Implementing reflective practice approaches with elite team athletes: Parameters of success. Reflective practice, 10, 353-363. doi: 10.1080/14623940903034721

Ritchie, J., Lewis, J., \& Elam, G. (2003). Designing and selecting samples. In J. Ritchie, \& J. Lewis (Eds.), Qualitative research practice: A guide for social science students and researchers (pp. 24-46). London, UK: Sage.

Rutter, M. (1987). Psychosocial resilience and protective mechanisms. American Journal of 
Orthopsychiatry, 57, 316-331. doi: 10.1111/j.1939-0025.1987.tb03541.x

Rutter, M. (2000). Resilience reconsidered: Conceptual considerations, empirical findings, and policy implications. In J. P. Shonkoff, \& S. J. Meisels (Eds.), Handbook of early childhood intervention (pp. 651-882). New York City, NY: Cambridge University Press.

Seery, M. D., Holman, A. E., \& Silver, R. C. (2010). Whatever does not kill us: Cumulative lifetime adversity, vulnerability and resilience. Journal of Personality and Social Psychology, 99, 1025-1041. doi: 10.1037/a0021344

Seibert, S. E., Kraimer, M. L., \& Crant, J. M. (2001). What do proactive people do? A longitudinal model linking proactive personality and career success. Personnel Psychology, 21, 845-874. doi: 10.1111/j.1744-6570.2001.tb00234.x

Siltaloppi, M., Kinnunen, U., \& Feldt, T. (2009). Recovery experiences as moderators between psychosocial work characteristics and occupational well-being. Work and Stress, 23, 330-348. doi: 10.1080/02678370903415572

Simonton, D. K. (1999). Significant samples: The psychological study of eminent individuals. Psychological Methods, 4, 425-451. doi: 10.1037/1061-4087.54.4.252

Smith, J. A. (2011). Evaluating the contribution of interpretative phenomenological analysis. Health Psychology Review, 5, 9-27. doi: 10.1080/17437199.2010.510659

Smith, J. A., Jarman, M., \& Osborn, M. (1999). Doing interpretative phenomenological analysis. In M. Murray \& K. Chamberlain (Eds.), Qualitative health psychology: Theories and methods (pp. 218-240). Thousand Oaks, CA: Sage.

Smith, J. A., \& Osborn, M. (2003). Interpretative phenomenological analysis. In J. A. Smith (Ed.), Qualitative psychology: A practical guide to research methods (pp. 51-81). London, UK: Sage.

Sonnenfield, J., \& Ward, A. (2008). How great leaders rebound after career disasters. 
Sonnentag, S., \& Fritz, C. (2007). The recovery experience questionnaire: Development and validation of a measure for assessing recuperation and unwinding from work. Journal of Occupational Health Psychology, 12, 204-221. doi: 10.1037/1076-8998.12.3.204

Sparkes, A. C., \& Smith, B. (2009). Judging the quality of qualitative inquiry: Criteriology and relativism in action. Psychology of Sport and Exercise, 10, 491-497. doi:10.1016/j.psychsport.2009.02.006

Spreitzer, G. M., Sutcliffe, K., Dutton, J., Sonenshein, S., \& Grant, A. M. (2005). A social embedded model of thriving at work. Organization Science, 16, 537-549. doi: $10.1287 /$ orsc. 1050.0153

Sutcliffe, K. M., \& Vogus, T. J. (2003). Organizing for resilience. In K. S. Cameron, J. E. Dutton, \& R. E. Quinn (Eds.), Positive organizational scholarship: Foundations of a new discipline. San Francisco, CA: Berrett-Koehler.

Tracy, S. J. (2010). Qualitative quality: Eight “big-tent” criteria for excellent qualitative research. Qualitative Inquiry, 16, 837-851. doi: 10.1177/1077800410383121

Ungar, M. (2003). Qualitative contributions to resilience research. Qualitative Social Work, 2, 85-102. doi: $10.1177 / 1473325003002001123$

Wadey, R., Clark, S., Podlog, L., \& McCullough, D. (2013). Coaches’ perceptions of athletes' stress-related growth following sport injury. Psychology of Sport and Exercise, 14, 125-135. http://dx.doi.org/10.1016/j.psychsport.2012.08.004 